\title{
Developing empathy towards older adults in design
}

\section{Burçak Altay}

To cite this article: Burçak Altay (2017) Developing empathy towards older adults in design, Educational Gerontology, 43:4, 198-208, DOI: 10.1080/03601277.2016.1273733

To link to this article: https://doi.org/10.1080/03601277.2016.1273733

Accepted author version posted online: 21

Dec 2016.

Published online: 06 Feb 2017.

Submit your article to this journal ¿त

III Article views: 269

Q View related articles $₫$

View Crossmark data $₫$

Citing articles: 1 View citing articles $ک$ 


\title{
Developing empathy towards older adults in design
}

\author{
Burçak Altay \\ Department of Interior Architecture and Environmental Design, Bilkent University, Ankara, Turkey
}

\begin{abstract}
In design disciplines, an affective understanding of users' everyday lives can increase designer sensitivity and awareness, leading to higher-quality design outcomes. Developing students' empathic understanding within design education is required to accomplish this goal. This article discusses learning strategies that enhance students' empathic horizons, and specifically analyzes an assignment conducted in an Interior Architecture and Environmental Design course, "The Grandparent Experience." Here, exposure through observation and interviewing, and art-based methods are employed to develop students' empathy towards older adults. We conducted a survey with students who completed the exercise and the course, exploring their perspectives on their learning. The results reveal that students had positive views on the assignment's effectiveness regarding the learning outcome and learning process. Implications for empathic design education and educational gerontology are discussed.
\end{abstract}

\section{Introduction}

Design disciplines are mainly concerned with creating products and spaces in order to increase the quality of life and experience of those who interact with and use them. However, design problems are 'wicked' in the sense that they require solutions created by the designer within an uncertain and undefined landscape of problem space, where a large range of information and knowledge is encountered. Therefore, as crucial as acquiring the adequate knowledge related to diverse users, an attitude that prioritizes those users is paramount. Designers need to acknowledge, understand and care for the psychological and physiological conditions and requirements of people, applying a usercentered approach. A user-centered approach incorporates inclusive design, or universal design, which aims for the design of artifacts and spaces that everybody can use and access, without a necessity for help, adaptation or change in the design (The Center for Universal Design, 1997). Thus, a user-centered design practice requires an empathy with the diverse users who vary in age, sex, as well as capabilities.

In design disciplines, empathic understanding refers to going beyond one's designer role to embrace the role of the user that engages with the environment/product (Kouprie \& Visser, 2009). In empathic design, rather than seeing users as abstract entities to provide merely functional solutions, designers are able to comprehend the lives, experiences, aspirations, and challenges of diverse populations, thus making emotional connections with them. Empathic strategies allow incorporation of these aspects into potential design solutions (McDonagh \& Thomas, 2010). Embedding real life into the design process, that is, expanding design beyond measurements and numbers, may spark designers' desire to feel for the users and encourage inspirational outcomes that respect individuals' specific experiences (Dankl, 2013; McGinley \& Dong, 2011).

When the target users have characteristics different from that of the designers, such as differently abled people, the elderly and children, a mismatch between the user needs and the designed environment is likely

CONTACT Burçak Altay burcak@bilkent.edu.tr Department of Interior Architecture and Environmental Design, Bilkent University, Bilkent, Ankara 06800, Turkey.

(c) 2017 Taylor \& Francis 
to occur. For example, the aging population in Turkey has specific needs and requirements that should be considered in the design of physical environments, to ensure a high quality of life for them. However, in both public and residential spaces, older adults experience many constraints related to a lack of support of the environment (Afacan, 2008; Türel,Yiğit, \& Altuğ, 2007). Most of the problems that occur due to the user-environment mismatch can be solved during the design phase if the designers can relate to and understand the needs of older adults.

Promoting designer awareness starting from the educational context is particularly important because practice constraints such as time, financial restrictions and stakeholder priorities limit the use of empathic strategies (McAdams \& Kostovich, 2011; Postma, Zwartkruis-Pelgrim, Daemen, \& Du, 2012). Previous research that adopt a user-centered approach in education has revealed that the cognitive and affective learning, i.e. what is learned, is highly influenced by the learner-centered instruction methods, i.e. how it is learned (Altay, 2014). Within this context, empathic strategies that give significance to user experience via student engagement are appropriate, as Campbell and McDonagh propose:

Empathic approaches may help place student designers outside their own comfort zone and within the life world of another person; empathy is a crucial quality for designers who wish to design products that will improve the lives of others. (2009, p. 605)

Many methods can be applied to encourage empathic understanding, which are discussed extensively by educators (Altay \& Demirkan, 2014; Kouprie \& Visser, 2009; McDonagh \& Thomas, 2010; Morrow, 2002). Among these, exposure through interview and observation, and art-based engagement have proved to be successful educational strategies.

\section{Exposure through interview and observation}

Contact and interaction with others help us develop our empathic horizons and remove stereotypes and negative perceptions (Chonody, 2015; McDonagh \& Thomas, 2010). In design education, Morrow states that students should come into direct contact with a varied range of user groups to increase sensitivity to personal experience (2002). She suggests that doing so will enable designers to integrate user requirements successfully.

Upon a review of the literature around educational approaches, Chonody (2015) reports that direct experience and exposure have a positive effect on student knowledge acquisition about and attitude change toward the elderly. Regarding the assessment of person-environment fit, Helle, Iwarsson, and Brandt (2014) hold the view that mere knowledge on body sizes and ergonomic measurements are inadequate for designing accessible environments. They suggest that an activity-based approach that focuses on the interaction of the individual with the physical environment in real-life processes can capture its subtle, broad and complex nature. Thus, many studies reveal that interaction with older adults enables students to better understand their lives and experiences (Ortiz, Cross, \& Day, 2012). Various exposure strategies include: older adults participating in a course interacting with younger adults (Knapp \& Stubblefield, 2000; Ortiz et al., 2012); creating partnerships with students and elders through special programs (Lu, Hoffman, Hosokawa, Gray, \& Zweig, 2010); encouraging undergraduate students to assume a range of responsibilities in research projects regarding aging (Laver, 2006); conducting interviews with elders in their homes (Stafford, 2001) and students carrying out participant observation in health or human service settings (Hughes \& Heycox, 2008).

\section{Art-based methods}

Art-based methods can provide ways to enable students to connect with others. Drawing on the close relationship between art and empathy, Lapum, Ruttonsha, Kathryn Church, Yau, and David (2012) argue that creative arts can alter our existing understandings of lives and experiences different from ours and immerse us in others' perspectives. The use of the arts in education helps incorporate 
creativity into the humanities and capture dimensions of the human experience that are impossible to achieve through academic writing alone (Bochner \& Ellis, 2003; Lapum et al., 2012).

Considering design practice, McGinley and Dong (2011) argue that we should go beyond resources presented primarily through text and numeric measurements and find ways to represent the needs of individuals at a deeper level through strategies that communicate the richness of human experience. They suggest that visual methods in particular, such as video and photographs, accompanied by thick descriptions that reveal the life stories and encounters of the actual individuals in context, are more appropriate for designers.

In gerontology education, use of documentary-film making, nonfiction narratives and photo-slide shows have been utilized and found to engage and motivate students (Lee, 2012). Based on research outcomes, Chonody (2015) also argues for the creative and unique use of current technology as well as artbased approaches such as sketches, photography and other imagery in gerontology education.

Within the Human Factors/Ergonomics course in an interior design department, "The Grandparent Experience" applies these strategies to develop empathy of the students toward older adults. Through student assessments, the current study explores the impact of the course module on student learning outcomes and learning process.

\section{The study}

\section{The educational context}

Within the curriculum of the Interior Architecture and Environmental Design Department of Bilkent University, Ankara, Human Factors is a second-year single-semester course. The main objective of the course is to enhance students' understanding and awareness of human factors knowledge and develop skills of product and space analysis, evaluation and design. By following this guideline, students are encouraged to consider the needs, requirements, capabilities, as well as psychological and physiological characteristics of older adults.

With the goal of increasing students' empathic understanding and exposure to the diversity of user groups, the instructors have developed a variety of educational methods in the course (Altay, 2014; Altay \& Demirkan, 2014). To encourage students to understand how the elderly experience their living environments, an assignment called "The Grandparent Experience" was introduced in 2012 (Altay, 2013). Upon viewing the positive impact of the exercise, instructors have conducted it in every semester since - from 2012 to 2016 - with 360 students in total participating.

\section{"The Grandparent Experience" assignment}

As the main activity in the exercise, the students worked in pairs and visited one of the students' grandparents' homes (age range 66-91). In the visit, students were to focus on the relationship/experience of their grandparents in their living environments.

A standard questionnaire was given to the students with which to structure their visit and base their interviews on. The inquiry focused on a) the positive or negative relationship of the grandparents with their environment's physical features; b) how they adapted to their environments to increase their quality of life; c) their favorite place in the home; and d) changes they would prefer in the environment to make it more appropriate for their needs. The students also analyzed these issues using participant observation and visual recording through sketches and photographs.

After the visit, students presented their findings through posters highlighting their own focus and priorities, during two lecture hours. Thus, while individual student visits revealed opportunities for unique understandings, the sharing of all cases ensured a comparison of commonalities and differences among the experiences. A rich variety existed in the design and content of these posters (Altay, 2013). 
Following class discussions, posters were displayed in the department halls. In this way, each semester students had a chance to see their peers' work. The poster exhibition allowed students to bring the experience out of the classroom to offer the opportunity for the wider learning community to empathize with the elderly.

\section{Method and procedure}

For three consecutive semesters 2014-2016, the Human Factors course was carried in six course sections with approximately 32 students per section (total of 192 students). Immediately after the class presentations and exhibit, a survey was handed out to the students requiring their feedback on learning. A total of 166 of the students completed the survey ( $86 \%$ response rate). The following research questions were explored:

(1) - Did the students find "The Grandparent Experience" educative?

(2) - How did they view their learning outcomes and process of the grandparent visit?

(3) - How did they view their learning outcomes and process of peer presentations?

Upon handing in the survey form, students were told that the results would only be used for educative and research purposes. They were not required to write their names. The majority of students were Turkish nationals from upper-middle-class families, with only five international students. Out of 166 respondents, $124(75 \%)$ were female and $42(25 \%)$ were male, ranging in age from 18 to 24 .

The survey form was composed of a total of two closed-ended and two open-ended questions. Separately for the grandparent visit and the presentations, the first questions asked (on a five-point scale) whether students thought the exercise was useful and educative. The open-ended questions asked them to reflect on their learning and experience of the exercise. Since both the course and survey were conducted in English, there were no translation issues in the data analysis phase.

\section{Data analysis}

According to the study's objectives, the first question was analyzed through descriptive statistics (means and percentage frequency distribution). Data obtained from the open-ended questions aimed to gather information about students' viewpoints (Creswell \& Clark, 2007) and was subject to a qualitative analysis. Student comments ranged between one and five sentences and were coded according to the emergent major themes and subthemes (Boyatzis, 1998). They were thus data-driven. As Creswell and Clark (2007) suggest, using both qualitative and quantitative data provides a more comprehensive understanding by noting trends in addition to participants' perspectives. In that respect, we introduce the major themes in the findings with frequency distributions to indicate trends, whereas we elaborate on subthemes in the text.

\section{Results}

As evident from the results to the first question, students felt the project was effective for their development in the profession (see Table 1 below).

Table 2 presents the major themes resulting from the analysis of the open-ended questions.

The analysis was carried out initially differentiating the major categories of the responses regarding learning outcome and learning process. It should also be noted that, apart from the identified themes that are more specific in nature, 38 of the students $(22 \%)$ stated in the open-ended questions that the project was "educative," "efficient" and "effective," thus reinforcing the closed-ended questions.

When thematic coding was made, subthemes also emerged related to the primary themes. The subthemes that are repeated and stand out will also be mentioned during analysis of the findings. 
Table 1. Student responses to the first two questions.

\begin{tabular}{llc}
\hline Ques. & \multicolumn{1}{c}{ Response } & Average \\
\hline I & "The Grandparent Experience" VISIT was educative in & 4.55 \\
& terms of Human Factors & 4.45 \\
II & Listening to friends' works and presentations educative in & \\
& terms of Human Factors & \\
& (1: Totally disagree; 2: Disagree; 3: Neutral; 4: Agree; 5: & \\
& Totally agree) & \\
\hline
\end{tabular}

Table 2. Emergent themes from student comments on their learning.

\begin{tabular}{|c|c|c|c|c|c|}
\hline & & \multirow[b]{2}{*}{ Major emergent themes } & \multicolumn{3}{|c|}{ Number and percentage (in brackets) of student responses $(N=166)$} \\
\hline & & & Total & My visit & Peer work \\
\hline \multirow[t]{3}{*}{ Learning Outcome } & 1 & $\begin{array}{l}\text { General recognition of } \\
\text { problems/solutions/adaptation }\end{array}$ & $145(87 \%)$ & $116(70 \%)$ & $102(61 \%)$ \\
\hline & 2 & $\begin{array}{l}\text { Valuation of inclusive design and } \\
\text { designer responsibility }\end{array}$ & $70(42 \%)$ & $56(34 \%)$ & $18(11 \%)$ \\
\hline & 3 & $\begin{array}{l}\text { Specific design } \\
\text { observations/considerations }\end{array}$ & $56(34 \%)$ & $22(13 \%)$ & $41(25 \%)$ \\
\hline \multirow[t]{3}{*}{ Learning Process } & 4 & Real-life/experiential quality & $46(28 \%)$ & $42(25 \%)$ & $6(4 \%)$ \\
\hline & & Enjoyable quality & $26(16 \%)$ & $24(14 \%)$ & $3(2 \%)$ \\
\hline & 6 & Limitations & $9(5 \%)$ & $7(4 \%)$ & $2(1 \%)$ \\
\hline
\end{tabular}

Note. "Total" includes student comments either to learning from "my grandparent visit" or from "peer presentations."

\section{General recognition of problems/solutions/adaptation}

The qualitative analysis of the survey yielded three major themes regarding learning outcomes, comprising both knowledge and attitudes. The first theme was general recognition of difficulties, problems and adaptation encountered by grandparents. Many students acknowledged difficulties and problems: "Grandparents have difficulty in their homes and some measurements don't fit them"; "I learned to identify lots of problems and what is good and bad for the elderly." Others noted an increased awareness regarding human factors knowledge and dimensions, as well as the house in relation to elderly needs and capabilities:

It was a very beneficial exercise in terms of raising awareness according to space and object observation. While we made this research, I learned a lot of things about daily problems which appear because of wrong design, and became more careful in analyzing designs.

Within problem recognition, an emergent subtheme (noted by 25 students, 15\%) was students' comparison of the grandparent experience with those of young adults. Students highlighted that there were discrepancies between the built environment and elderly requirements, since the environment was not designed for them. Consequently, many students "understood the environment from an elderly perspective" and could empathize with their elders, recognizing the impact of the environment on their physiological and psychological conditions:

Aspects that we had never thought would be problematic due to our own age caused problems for my grandparents. For example, we don't have knee or back aches. This assignment helped us see the environment from their viewpoint.

During the second phase, there were also students who thought seeing other projects and presentations were "enlightening," allowed them to gain new perspectives and "expanded their horizons."

Across the phases, students pinned down their problem identifications compared to their prior knowledge. For example, especially during their visit, students were amused and surprised that they realized problems they (and others) had not noticed or ignored previously (noted by 26 students, $15 \%$ ): 
This was an educative and shocking experience for me ... Many problems exist in the homes that are not noticed at first and often disregarded by designers.

I learned the causes of some problems, as well as their solutions, that we encounter in daily life but do not pay too much attention.

Meanwhile, in the second phase, with the visit completed, the students now stressed on the problems and solutions that they learned from peer presentations that they had not encountered in their own visit, and thus were different (noted by 32 students, 19\%). Thus, an accumulative nature of the knowledge could be observed:

I've learned to explore different people's houses with respect to human diversity, ergonomics and universal design. Although we searched the same topic, due to the human factors, we all experienced different issues and learned different solutions.

In addition to many different problems and solutions in elderly homes, peer presentations allowed students to see that many elderly had common and similar problems (38 students, 22\%). Some stated seeing comparable problems across many examples and cases allowed them to pay more attention.

Besides observation and analytical skills, 21 students (13\%) remarked that the project increased their creative design abilities. "Brainstorming" with their peers also enhanced this process: "It developed critical thinking about what factors can be considered while designing and how to provide solutions to problems faced by grandparents." Moreover, students began creating design solutions in their own homes, whereas one student actually made changes in her grandparents' house with resolution of some of her problems, thus applying what she had learned accordingly. Another student reflected her views:

Whenever I go to a house, I analyze it from an ergonomics standpoint. Previously, I was not aware that required dimensions would vary so much according to different people. This way, new design ideas emerged in my mind and I feel these will help in my future projects.

During the assignment, students (26 people, 16\%) also noted how elderly adapted to situations, however problematic they might be. The adaptation was sometimes admired and positively reflected; at other times problematized: "Even though they have problems, most grandparents adapt to situations and are happy!"; "They are forced to adapt to the situations despite the difficulty." Thus, many students realized that the elderly should not have to adapt themselves to difficult situations, calling for the role of the designer and a valuation of inclusive design.

\section{Valuation of inclusive design and designer responsibility}

The second theme, interrelated with the first one, was students' valuation of inclusive design and designer responsibility. Rather than indicating how things are, it touched upon how things ought to $b e$. While some students focused especially on designing for the elderly, others suggested that design should consider everyone's needs. The following comments illustrate these attitudes:

Equitable design is very important. While designing a house, the designer has to consider the ergonomics, physiology, and psychology of elderly people.

We should improve ourselves as designers and develop a design-for-all approach considering everyone regardless of age.

Some students related their understanding the elderly perspective to valuation of inclusivity: "It has enabled me to empathize with the elders. Getting older or being disabled is unavoidable fact of life. So, we should consider all ages and circumstances to design equally."

There were more accounts of valuation of inclusive design for the visit as compared to the peer projects. This finding could be for several reasons. First, immersion into real-life experience and direct contact with a user/client is likely to have a great influence on the affective component of learning, and thus result in 
increased student valuation and professional responsibility. Another reason for this difference may be because the student already understood the importance of universal design during her visit experience and did not need to mention it in the peer presentation process.

As a subtheme of the positive attitude toward inclusive design, some students made a specific reference to how the project enhanced their own designer identity. Thus, they felt empowered to change problematic conditions through design. Others, previously mentioned, also believed this assignment would help them in their designs and projects. The following quotes illustrate this attitude, also revealing how the experiential learning process enhanced her view:

As a designer I felt like I can change people's world with small touches. Only small differences can make people comfortable. Sitting with old people and discuss about design problems opened my eyes and I want to help people.

\section{Specific design observations/considerations}

The third theme is related to specific design observations/considerations. These included remarks pointing out to a certain difficulty encountered by the resident, or a contained, specific problem recognition in the environment. Many specific observations referred to the main problematic activities of older people, such as bending, reaching, carrying, accessing, circulating and sitting. It also included recognition of the major rooms and areas that problems occurred, such as reaching problems in kitchens, accessibility problems in bathrooms, difficulty regarding stairs, etc. Interrelated comments were made with respect to specific furniture, such as high shelves and storage, high bathtubs, high see-through hole of doors that cause lack of security, deep or high furniture and bathtub, and a requirement for elevators where the buildings lacked one. The need for comfortable spaces and requirements around relaxation was also recognized, such as the functionality and use of living rooms, utilization of balconies that related to the exterior views and atmosphere, and bedrooms with accessible beds and equipment. It was also acknowledged that flexibility and creating adaptable products and spaces are critical aspects of design.

Across phases, students had greater recognition of specific design observations in peer projects compared with personal visits. This finding implies that repetition of certain knowledge and its reinforcement through different means increase student awareness and acknowledgement of issues, some of which may not seem to be apparent in singular visits. The following student perspective regarding the peer presentations reveals her recognition of specific design considerations followed by a valuation of inclusive design:

I learned that none of the old people are comfortable with kitchen cabinets. In addition, bathroom is very problematic for them, particularly accessing the bathtub. As interior designers we should be capable of solving these problems so that they do not encounter these.

In addition to comments related to the learning outcomes, students also commented on the positive aspects of the learning process (see Table 2). Phase-specific responses were apparent due to different students' engagement with course material.

\section{Experiential/real-life quality}

The most common theme that was mentioned by the students was the experiential quality of the assignment, particularly in the first phase. Many students believed that the "real-life engagement" and the "actual experience" of observation and/or interviews provided an opportunity to understand the issues of human factors knowledge and reinforced their learning:

It was really good to experience a real residential area's potential in terms of ergonomics.

Our practicing and experiencing allowed us to observe and recognize the design faults better. 
It was very informative and important to go to people's houses and learn under which conditions they continued their daily lives. (...) Before, during and after design, their views and comfort should be considered.

As a subtheme under this major theme, 15 (9\%) students believed the "real life" encounter reinforced what they learned in the course lectures, enabling them to apply what they learned in theory to practice:

I was able to compare the knowledge in school with real life and learned the necessity for universal design by living and experiencing it.

We made practice with the grandparent's houses, we used our lessons notes and information while doing the project. We learned how to look at elderly houses.

Moreover, six students also thought that this assignment was much more effective than pure theoretical exposure and examples given in lectures only. They mentioned that knowledge settled better in their minds and memories.

Even though there were fewer comments related to the real-life learning for the second phase, singular comments reflected also on the positive attributes of the second phase. Thus, as previously mentioned, students indicated viewing other presentations as noteworthy in enhancing similar problems, identifying different problems and generation of distinct design solutions. While a few students found the visual focus of presentations educative, they also reflected on their own project presentations, in terms of format and contents: "When I was listening to the presentations I wished I could re-create my own work through distillation of all the findings."

Although not a focus of the majority of students, one student also noted that visiting with a friend was educative since they complemented one another in the critical analysis of problems and finding solutions. Thus, collaborative learning was appreciated.

\section{Enjoyable quality}

A positive theme that emerged from the students' perspectives on their assignment was enjoyment of the process. Thus, "I enjoyed the assignment" was very common comment within the interviews. This enjoyment at times supported the enhancement of professional identity:

For me, the assignment was both educative and enjoyable. When I was interviewing them, learning about their requirements, and taking dimensions I found myself suitable for this profession and understood that I will carry it out with happiness.

Moreover, some students also commented that not only did they enjoy the visit, but also the visit made their grandparents happy. Positive learning experience was thus interactive:

This assignment gave us a chance to strengthen our bonds and relationships with our grandparents. We had a quality time with them. Moreover, we are now able to understand how they feel about problems in their house and how they adapt to and overcome them.

Meanwhile for the second phase, with interrelated themes, a joyful recognition of certain adaptations at the same time encouraged professional identity for one student:

I enjoyed the presentations. They contributed to my experience in terms of other types of complaints by grandparents. Also the grandparent's daily use of a pilates ball (for support of his legs when sitting) caught my interest. Now, I feel like an interior architect!

\section{Limitations}

On the contrary to the majority who believed that the process was effective, nine students (5\%) stated problems and challenges. For example, some students found it difficult to access a grandparent in the first place, or carry out the interview since the grandparents were hesitant. Due to such difficulties, they suggested that the process would be easier if they analyzed their own environment 
rather than going to a particular person. Meanwhile, two other students expressed their disappointment in 'wasting too much time' either to the visit, or to the presentation listening, since most of the issues raised could have been predicted and revealed solely through the lectures. Moreover, one had difficulty in seeing the presentations and posters in the lecture class, suggesting another method of presentation.

In addition to the challenges, some students also suggested similar assignments to continue in this course, such as visiting hospitals and child-care centers, or to be applied in other theoretical courses as well as design studios.

\section{Discussion}

Promoting and enhancing student interaction with and empathy for an older population are explored in this study within the specific context of design education in a Human Factors course in Interior Architecture. In "The Grandparent Experience," students had direct contact with their (or their peers') grandparents, observing and interviewing them in their home environment. Students visually shared their findings with peers through poster presentations as well as exhibition. Collaborative learning took place in both phases; whereas students made their grandparent visit and prepared their findings in pairs, they all strengthened their knowledge through listening to peer presentations.

The study questioned student learning at different phases of the module. Descriptive statistics and qualitative analyses were used to analyze student answers to structured and open-ended questions. The study findings support earlier research results that facilitating exposure to the lived experience of older adults (Chonody, 2015; Knapp \& Stubblefield, 2000; Laver, 2006; Marken, Moxley, \& Fralwy, 2011; Ortiz et al., 2012; Stafford, 2001) and encouraging student immersion in art-based methods (Aditomo, Goodyear, Bliuc, \& Ellis, 2011; Campbell \& McDonagh, 2009; Lee, 2009, 2012) have a positive impact on the development of their knowledge and attitude. Moreover, the findings reveal that students found the experiential aspect of the process as positive and displayed motivation and enjoyment. The findings indicate that each learning method has its own potential and strengths, and as such, a module that encourages a multi-method approach can cultivate student learning in diverse ways.

The study provides a basis for further in-depth qualitative studies and structured quantitative surveys that explore at length the major themes emerging from student comments. The same methods applied in different contexts may yield different results, particularly for distinct design and social science disciplines. However, instructors can adjust and shift the module's emphasis according to the disciplinary focus.

One of the main limitations of the study was to apply a single survey after the completion of the module, which might have affected the results of student perspectives on their learning at different stages. Thus, quantitative and qualitative surveys carried out at the beginning and end of the distinct stages would increase result reliability. Similarly, research could be done with control groups, where different learning phases are isolated to clarify their impact. Moreover, longitudinal studies that question the impact of student learning over consecutive years could reveal the long-term effects of the course process.

Design education and practice should incorporate not only objective data, indirect research findings and global concepts, but also subjective understanding, one-to-one interaction and local, real-life knowledge. Thus, the limited acquisition of knowledge possible through textbooks and other indirect means can be overcome by students constructing and cocreating their own knowledge, as well as by being active participants in disseminating their findings and interpretations to the wider community. By making connections with potential design users, students can expand their empathic horizons and become immersed in and inspired by actual experiences, thus creating better livable environments. Contact with first relatives offers this opportunity for novice researchers in an educational context, while providing a basis for further communication in professional life.

The empathic design approach applied in this course can be replicated both in design education across cultures/regions and in other fields of social sciences focusing on gerontology (or, e.g., special needs) education. There is a call for interdisciplinary methods that enhance learning not only in the cognitive 
domain but also in the affective domain so that students can develop or enhance an attitude of caring and responsibility as part of their professional identities. These experiences will help positively shape and cultivate their associated professional values, as well as their application in their careers.

\section{References}

Aditomo, A., Goodyear, P., Bliuc, A., \& Ellis, R. (2011). Inquiry-Based learning in higher education: Principal forms, educational objectives, and disciplinary variations. Studies İn Higher Education, 32(9), 1239-1258. doi:10.1080/ 03075070.2011 .616584

Afacan, Y. (2008). Designing for an aging population: Residential preferences of the Turkish elderly to age in place. In P. Langdon, P. J. Clarkson, \& P. Robinson (Eds.), Designing inclusive futures (pp. 241-252). London, UK: Springer.

Altay, B. (2013). Design education with empathy: The grandparent experience. In the proceedings of Crafting the Future, 10th International European Academy of Design Conference, Gothenburg, Sweden, April 13-15. Retrieved from http://www.craftingthefuture.se/

Altay, B. (2014). User-centered design through learner-centered instruction. Teaching İn Higher Education, 18(2), 138155. doi:10.1080/13562517.2013.827646

Altay, B., \& Demirkan, H. (2014). Inclusive design: Developing students' knowledge and attitude through empathic modeling. International Journal of Inclusive Education, 19(2), 196-217. doi:10.1080/13603116.2013.764933

Bochner, A. P., \& Ellis, C. (2003). An introduction to the arts and narrative research: Art as inquiry. Qualitative Inquiry, 9 (4), 506-514. doi:10.1177/1077800403254394

Boyatzis, R. E. (1998). Transforming qualitative information: Thematic analysis and code development. Thousand Oaks, CA: Sage Publications.

Campbell, L. H., \& McDonagh, D. (2009). Visual narrative research methods as performance in industrial design education. Qualitative Inquiry, 15(3), 587-606. doi:10.1177/1077800408318306

Chonody, J. M. (2015). Addressing ageism in students: A systematic review of the pedagogical intervention literature. Educational Gerontology, 41, 859-887. doi:10.1080/03601277.2015.1059139

Creswell, J. W., \& Clark, V. P. (2007). Designing and conducting mixed methods research. London, UK: Sage.

The Center for Universal Design. (1997). The principles of universal design, Version 2.0. Raleigh: North Carolina State University. [online]. Retrieved January 14, 2011, from http://www.ncsu.edu/www/ncsu/design/sod5/cud/about_ud/ udprinciplestext.htm>

Dankl, K. (2013). Style, strategy and temporality: How to write and inclusive design brief? The Design Journal, 16(2), 159-174. doi:10.2752/175630613X13584367984866

Helle, T., Iwarsson, S., \& Brandt, A. (2014). Validation of housing standards addressing accessibility: Exploration of an activity-based approach. Journal of Applied Gerontology, 33(7), 848-869. doi:10.1177/0733464813503042

Hughes, M., \& Heycox, K. (2008). Using observation for reflective practice with older people. Educational Gerontology, 34(3), 185-205. doi:10.1080/03601270701835841

Knapp, J. L., \& Stubblefield, P. (2000). Changing students' perceptions of aging: The impact of intergenerational service learning course. Educational Gerontology, 26(7), 611-621. doi:10.1080/03601270050200617

Kouprie, M., \& Visser, F. S. (2009). A framework for empathy in design: Stepping into and out of users' life. Journal of Engineering Design, 20(5), 437-448. doi:10.1080/09544820902875033

Lapum, J., Ruttonsha, P., Kathryn Church, K., Yau, T., \& David, A. M. (2012). Employing the arts in research as an analytical tool and dissemination method: Interpreting experience through the aesthetic. Qualitative Inquiry, 18(1), 100-115. doi:10.1177/1077800411427852

Laver, G. D. (2006). Expanding the educational horizons of undergraduates through cognitive aging research. Educational Gerontology, 32(7), 539-551. doi:10.1080/03601270600723734

Lee, N. (2009). Project methods as the vehicle for learning in undergraduate design education: A typology. Design Studies, 30(5), 541-560. doi:10.1016/j.destud.2009.03.002

Lee, T. (2012). Getting to know you: Using documentary video-making to challenge ageist stereotypes. Gerontology \& Geriatrics Education, 33(3), 272-286. doi:10.1080/02701960.2012.661810

Lu, W., Hoffman, K. G., Hosokawa, M. C., Gray, M. P., \& Zweig, C. (2010). First year medical students' knowledge, attitudes, and interest in geriatric medicine. Educational Gerontology, 36(8), 687-701. doi:10.1080/03601270903534630

Marken, D. M., Moxley, B., \& Fralwy, A. K. (2011). Safe and independent: Enriching lives through service-learning. Journal of Applied Gerontology, 30(4), 505-512. doi:10.1177/0733464810368401

McAdams, D. A., \& Kostovich, V. (2011). A framework and representation for universal product design. International Journal of Design, 5 (1), 29-42.

McDonagh, D., \& Thomas, J. (2010). Disability+ relevant design: Empathic design strategies supporting more effective new product design outcomes. The Design Journal, 13(2), 180-198. doi:10.2752/175470710X12735884220899

McGinley, C., \& Dong, H. (2011). Designing with information and empathy: Delivering human information to designers. The Design Journal, 14(2), 187-206. doi:10.2752/175630611X12984592780005 
Morrow, R. (Ed.) (2002). Building and sustaining a learning environment for inclusive design. Final Report of the Special Interest Group in Inclusive Design for Centre of the Education in the Built Environment. Retrieved from http://cebe.cf.ac.uk/learning/sig/inclusive/full_report.pdf

Ortiz, D. V., Cross, S. L., \& Day, A. (2012). Insightful learning of life's lessons with older adult guests in the classroom. Educational Gerontology, 38(12), 854-866. doi:10.1080/03601277.2012.660844

Postma, C. E., Zwartkruis-Pelgrim, E., Daemen, E., \& Du, J. (2012). Challenges of doing empathic design: Experiences from industry. International Journal of Design, 6(1), 59-70.

Stafford, P. B. (2001). Teaching the ethnography of aging. Educational Gerontology, 27(7), 557-567. doi:10.1080/ 036012701753122893

Türel, H. S., Yiğit, E. M., \& Altuğ, İ. (2007). Evaluation of elderly people’s requirements in public open spaces: A case study in Bornova District (İzmir, Turkey). Building and Environment, 42(5), 2035-2045. doi:10.1016/j. buildenv.2006.03.004 